\title{
A Literature Review on Coach-Athlete Relationship in Table Tennis
}

Guillaume Martinent', Eirik Ansnes ${ }^{2}$

'University of Lyon, University of Claude Bernard Lyon I, Laboratory on Vulnerabilities and Innovation in Sport, France

${ }^{2}$ Fokus Table Tennis Club, Oslo

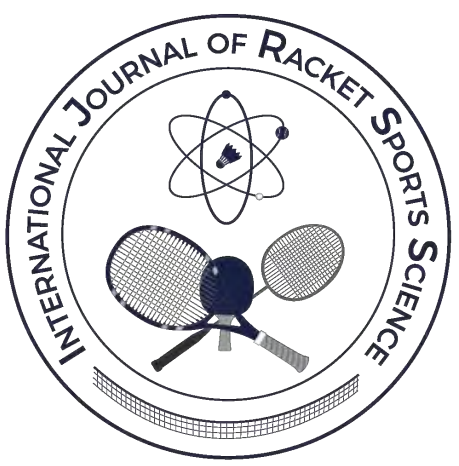

\section{Abstract}

Coach-athlete relationship is a salient factor in table-tennis as it impacts players' performance and well-being. The structure and set up in table tennis is often designed so the players and coaches are working together through many stages in the players' career. For instance, it is not uncommon for coaches of young table tennis players to accompany their respective players to the senior international elite level. Indeed, the access to the knowledge base regarding coach-athlete relationship represents a major issue for the different stakeholders involved in table-tennis (coaches, athletes, parents, sport psychologists, researchers). To that end, we firstly overviewed and discussed the different theoretical models exploring the concept of coach-athlete relationship to clarify the core dimensions of this construct. Secondly, we provided a rationale behind the salient role of coach-athlete relationship in table tennis by detailing its consequences in order to better understand the mechanisms underlying coach-athlete relationship. Thirdly, we addressed how table tennis coaches can develop and/or maintain an adaptive coach-athlete relationship, especially in reference to specific situations in table tennis. In conclusion, the coach-athlete relationship is a particularly important parameter in the daily life of the table tennis players due to its influence on their performance and well-being. Thus, it is essential that the coaches establish relationship promoting athletes' development throughout their career.

Keywords: Attachment Style, Autonomy Supportive Coaching Style, Coach Behaviour, Communication, Performance

Correspondence author: Guillaume Martinent

E-mail: guillaume.martinent@univ-lyon1.fr

Cite this article as:

Martinent, G., \& Ansnes, E. (2020). A Literature Review on Coach-Athlete Relationship in Table Tennis. International Journal of Racket Sports Science, 2(1), 9-21. 


\section{Introduction}

Literature in sport and organizational psychology suggests that the quality of leadership has a great impact on the performance of individuals (Jowett \& Poczwardowski, 2007; Mageau \& Vallerand, 2003; Schmink \& Wells, 1999). For instance, Schmink and Wells (1999) provided evidence that the behaviours of the leader (coach) relate to the performance of the team, and that $45-65 \%$ of an organization's success is determined by the team leader. Indeed, a growing amount of research has studied coach-athlete relationship in sport settings (Jowett \& Poczwardowski, 2007; Mageau \& Vallerand, 2003). As a whole, this literature showed that the type of leadership endorsed by the coach and its behaviours strongly impact athletes' behaviours, cognitions, motivation and emotions (Jowett \& Poczwardowski, 2007; Mageau \& Vallerand, 2003). Nevertheless, the win-at-all-cost atmosphere that can reign in sport setting (Cece, Guillet-Descas, Nicaise, Lienhart, \& Martinent, 2019) could potentially create an environment likely to impact coach-athlete relationship. In table tennis, coaches and their players share many experiences across sport career and it is not uncommon for coaches of young table tennis players to accompany their respective players to the senior elite level (Kajtna \& Kondric, 2009). Thus, as coaches and players spend a long career together, it makes stronger ties and boosts the influence of leadership (González-García \& Martinent, in press). Indeed, the access to the knowledge base regarding coach-athlete relationship represents a major issue for the different stakeholders involved in table-tennis (coaches, athletes, parents, sport psychologists, researchers). Therefore, in light of the importance of coach-athlete relationship in the field of table-tennis (GonzálezGarcía \& Martinent, in press; Kajtna \& Kondric, 2009; Li-Hua, Cheng-Hua, \& Chung-Hsiung, 2012), the present narrative review addressed literature examining this topic in sport and especially in table tennis. To facilitate understanding, our paper was organized into three main sections. The first section provided an overview and a discussion of the different theoretical models exploring the concept of coach-athlete relationship in order to clarify the core dimensions of this construct. The second section provided a rationale behind the salient role of coachathlete relationship in table tennis detailing its consequences in order to better understand the underlying mechanisms involved in coach-athlete relationship. The third section addressed how tabletennis coaches can develop (and/or maintain) an adaptive coach-athlete relationship, especially in reference to situations related to table tennis.

\section{What does coach-athlete relationship actually mean?}

This section provides a theoretical overview of the concept of coach-athlete relationship. This concept can be broadly defined as a situation in which a coach's and an athlete's cognitions, feelings and behaviours are mutually and causally interrelated (Jowett \& Poczwardowski, 2007). It is noteworthy that the coach-athlete relationship is expected to change over time due to the interaction between the coach and athlete (Jowett \& Poczwardowski, 2007). Beside the issue of the definition of the construct, several conceptual models of the coach-athlete relationship have been proposed within the sport literature (Jowett \& Poczwardowski, 2007; LaVoi, 2004; Mageau \& Vallerand, 2003; Wyllemann, 2000). Overviewing and discussing these theoretical models would allow depicting the core dimensions of the coach-athlete relationship construct in sport settings and thus in table tennis.

Whereas Poczwardowski's (1997) conceptual model suggested that coach-athlete relationship is a recurring pattern of mutual care, and both are influenced in the relationship, LaVoi's conceptual model (LaVoi, 2004) took a relational-emotional approach. In particular, he suggested that athletes would achieve higher level of satisfaction and growth when feeling optimally close and interdependent with the coach and teammates. Four qualities were conceptualized as being at the heart of the coachathlete relationship: Authenticity, engagement, empowerment, and the ability to deal with difference. 
Wyllemann's conceptual model (Wyllemann, 2000) emphasized that the relationship between the coach and athlete should be analysed according to the behaviours of both stakeholders during training sessions and competitions. In particular, three dimensions were conceptualised within this theoretical framework: Acceptance-rejection (the positive or negative attitude towards the relations), dominance-submission (there is a strong and a weak individual in the relationship) and social-emotional (taking a social or personal role in the relationship). Whereas this conceptual framework suggests that the athlete's and coach`s reciprocation and correspondence of behaviour is likely to occur on the field of play, it does not yet consider the reasons why, or the timing of the behaviours.

Based on the self-determination theory (Deci \& Ryan, 2000), Mageau and Vallerand (2003) proposed that coaches' personal orientation towards coaching, context, and perceptions of the athlete's behaviours and motivation influence coaching behaviours (autonomy-supportive behaviours, provision of structure and involvement) and in turn athletes' well-being (Mageau \& Vallerand, 2003). Although focusing and detailing an adaptive form of coach behaviour (autonomy-supportive behaviours) is particularly useful, this model doesn't encompass the wide variety of coach-athlete relationships encountered on the sporting ground. Finally, Jowett's conceptual model suggested that the athlete's and coach's behaviours, emotions and thoughts are mutually and causally interdependent according to the rule of the $3+1$ Cs: Closeness (trust and respect), commitment (intention to maintain the relationship), complementary (behaviours of dominance and submission), and co-orientation (establishment of a common ground in their relationship) (Jowett \& Pozcwardowski, 2007).

As a whole, compassion emerged as a vital part of the coach-athlete relationship in all the models. Most of the theoretical models also highlighted the causal reciprocity in the coach-athlete relationship. However, Mageau and Vallerand (2003) were the only ones to describe in a particularly comprehensive way the context surrounding an autonomy- supportive coaching style (a particularly adaptive coaching style).

\section{Why paying attention to coach-athlete relationship in table tennis?}

The coaching role is demanding and requires a variety of skills to be successful in any sport. There are a lot of issues to consider for optimizing coachathlete relationship such as the type of sports, the level of coaching or age of the athletes as well as surrounding factors like media, financial issues, pressure from the board and parent's involvement. Adjustments of the coach-athlete relationship need to be made by coaches to lead in the most suitable way in the actual context. In sport settings, the coach-athlete relationship is recognized as a salient factor promoting the development of athletes' physical and psychosocial skills (Dominteanu, 2011; González-García, Martinent, \& Trinidad Morales, 2019). Within the first section of this literature review, we provided evidence that the coach and athlete are mutually influenced by each other. So why is it so important to develop an adaptive coachathlete relationship in sport settings? Jowett and Poczwardowski (2007) argued that the ideal coachathlete relationship could lead to the two interrelated benefits of: (a) effectiveness that promotes personal growth for both the athlete and the coach; and (b) performance success (i.e., to achieve athletic excellence on the part of the athlete and professional excellence on the part of the coach).

To comprehensively represent research investigating coach-athlete relationship in tabletennis, we undertook an exhaustive search of the literature to locate published work relevant to this concept in table tennis using databases including PsycINFO, PsycARTICLES, Psychology and Behavioral Sciences Collection, and SPORTDiscus. As a first step, to locate published papers, we used the keyword table tennis, crossed with the keywords coach-athlete relationship, coach behaviours, coaching style or coach leadership. In a second step, we combined the keyword table-tennis with that of sport psychology. It is also noteworthy that the 
reference lists of all obtained articles were also examined for other relevant studies. Although it is generally recognized that narrative reviews commonly do not list the types of databases and the inclusion criteria (Cipriani and Geddes, 2003), providing some key elements about the search strategy allows the readers to better judge the transparency of the work (Campo, Mackie, \& Sanchez, 2019). Literature in sport settings and especially among table-tennis players detailed the consequences of coach-athlete relationship on a wide variety of athletes' outcomes (e.g., motivation, emotions, or well-being) (González-García \& Martinent, in press; Jowett \& Poczwardowski, 2007; Li-Hua et al., 2012; Mageau \& Vallerand, 2003).

Motivation is one of the most fundamental psychological attributes to achieve high performance in sport (Cece, Lienhart, Nicaise, Guillet-Descas, \& Martinent, 2018) and in particular in table tennis (Martinent \& Decret, 2015a). Several studies conducting among table tennis players showed that autonomous forms of motivation (behaviours performed by choice) are important determinants of optimal functioning, sport persistence and performance whereas the opposite pattern of results was observed for controlled forms of motivation (players feel pressured to practice table tennis) (Chu, Zhang, \& Hung, 2008; Martinent, Cece, ElferinkGemser, Faber, \& Decret, 2018; Martinent \& Decret, 2015a). Coach-athlete relationship plays a key role in the type of motivation endorsed by players (Mageau \& Vallerand, 2003). Coaches' autonomy support helps nurturing athletes' basic psychological needs and in turn fostering autonomous motivation (Mageau \& Vallerand, 2003). In particular, being autonomy-supportive means that a coach takes the athlete's perspective and acknowledges the other's feelings (Deci \& Ryan, 2000; Mageau \& Vallerand, 2003). Autonomy-supportive coaching style is consistent with the tenets of the Jowett's $3+1 \mathrm{Cs}$ theoretical framework (Jowett \& Poczwardowski, 2007) in which the coach's and the athlete's emotions and thoughts depend on the perception of closeness, commitment, complementary and coorientation. In this perspective, coach has to see the athlete as a whole and work comprehensively the relationship with the player to maximize the chance of fulfilling his or her potential. The style of coaching strongly impacts the quality of the coach-athlete relationship (Jowett \& Poczwardowski, 2007; Mageau \& Vallerand, 2003). As such, it is necessary for coaches to pay attention to the dynamics of the relationship. In the establishment of an effective and successful relationship the responsibility lays mostly with the coach as he or she is the grown-up person, and because of the power that follows with the role.

A coach-athlete relationship is developing as the athlete grows during the career. The athlete's awareness of the responsibility in the relationship should develop as well. In this way the coach and athlete can nurture and maintain the relationship (Jowett \& Poczwardowski, 2007). Indeed, it could be particularly useful to examine the topic of the coaching behaviour from the athlete's point of view. In this perspective, 447 competitive table tennis players in a University table tennis tournament attended in a study regarding their perception on coach's leadership behaviour (Li-Hua et al., 2012). Li-Hua et al. (2012) showed that awarding behaviours and training and guiding behaviours were the most experienced behaviours by players. These results suggest that University coaches' positive feedbacks and their effort in guiding players' skills and tactics during training were well recognized by their players. In contrast, autocratic behaviours received the lowest scores suggesting that coaches should minimize the use of such approach to avoid negative effects which may affect players' performance (Li-Hua et al., 2012). The ambiguous results regarding the effects of demographic variables on players' perceptions of coaches' leadership behaviours underlined the importance of adjusting coach behaviours according to the individual preferences of the players in order to optimize coachathlete relationship and in turn fulfil players' potential (Chelladurai \& Saleh, 1980; Li-Hua et al., 2012).

Coach-athlete relationship also plays a key role in the emotional experience of table tennis players through its impact on coping strategies (González- 
García \& Martinent, in press). This is particularly relevant as the abilities to manage emotions and to cope with stressful situations are considered by several sport psychologists and table tennis coaches as among the most powerful qualities that table tennis players must develop in their career (Kurimay, Pope-Rhodius, \& Kondric, 2017; Martinent \& Decret, 2015b; Martinent, Ledos, Ferrand, Campo, \& Nicolas, 2015). Because high psychological demands are placed on table tennis players, they have to struggle for controlling their emotions and it could impact their performance levels (Chen, Chang, Hung, Chen, \& Hung, 2010; Martinen, Campo, \& Ferrand, 2012). In particular, table tennis players use a wide variety of coping strategies to manage the demands exceeding their perceived resources (Kurimay et al., 2017) which can be regrouped into several coping dimensions including task-oriented coping (dealing directly with stressful situation and the resulting thoughts and affects), a coping dimension related to optimal functioning and performance (Gaudreau \& Blondin, 2002). Of particular importance in the context of the present study, democratic coaching behaviours (perceived from their players) significantly predicted players' task-oriented coping which in turn predicted positive emotions experienced by players during competition (González-García \& Martinent, in press). These results obtained in the field of table tennis were consistent with those observed among athletes practicing a wide range of other individual sports (Nicolas, Gaudreau, \& Franche, 2011).

In sum, a bulk of studies conducted among table tennis players provided evidence of the main role played by psychological factors (motivation, emotions, coping strategies) in both performance variability and players' well-being (Chu et al., 2018; Kurimay et al., 2017; Martinent \& Decret, 2015a, 2015b; Martinent et al., 2015, 2018). In line with this literature, a few studies provided evidence for the main role of coach-athlete relationship in table tennis (Kajtna \& Kondric, 2009; Li-Hua et al., 2012) and for the impact of coaches' behaviours on table tennis players' emotional outcomes (González-García \& Martinent, in press). Indeed, developing and maintaining an effective coach-athlete relationship should be of high interest for the coaches, the players and the sport psychologists in the field of table tennis.

\section{How coaches can develop and/or maintain a coach-athlete relationship fostering table-tennis players' well- being and performance}

\section{Attachment styles and establishment of the relationship between coach and athlete}

The attachment styles developed by children as they get older during their infants impact their relationships with adults such as coaches (Bowlby, 1982). Three attachment styles are postulated within this theoretical framework: (a) A secure attachment involves the confidence in availability of their close other to provide them with comfort and support and reduced distress upon proximity to the caregiver following separation; (b) An anxious (insecure) attachment refers to a strong desire for proximity with caregiver (even in non-distressing situations) and to the experience of upset (with the caregiver) following separation; and (c) An avoidant (insecure) attachment is characterized by very few (or almost no) attempts at maintaining contact with caregiver and thus little (or no) distress following separation (Davis \& Jowett, 2014; Drake, 2009; Felton \& Jowett, 2015; Harmon, Siegien, Watt, Rebers \& Pennington, 2015). Individuals with an anxious attachment can develop negative views of themselves because they have the perception they are not worthy of support or attention whereas individuals with avoidant attachment can develop negative connotations with others due to not receiving support in the past (Harmon et al., 2015).

New children coming to the table tennis hall are usually excited and probably a bit nervous as well. Because positive first impression and experience can lead them to come back to future training sessions, coaches should pay particular attention towards establishing of the relationship. Based on the attachment theory (Bowlby, 1982), coaches need to 
earn the child's trust and establish a secure base for the child.

A crucial factor for coaches to be aware of and consider is the child's attachment style. Understanding the psychological needs related to each attachment style might help coaches to adjust their behaviour and build that secure base (Harmon et al., 2015). In the initial interactions and conversations with the child and parents, it would usually be beneficial to establish a conversation directly with the child as well. Not only with the parents. Learning and remembering the child `s name is necessary as well in order to make the child feel that the coach cares about him or her as a person. In this initial interaction, coaches could notice clues about the child's attachment style and how protective the parents behave. For instance, children differ in how relaxed they are leaving their parents for taking part in the training and this situation could provide information about the attachment style of the child. Then, based on this information, coaches can decide how to take the next step establishing the relationship with the child.

As securely attached athletes typically have an easier time developing and maintaining relationships with parents and coaches, establishing a relationship with children with this attachment style will be easier for coaches (Harmon et al., 2015). Both anxious and avoidant patterns of attachment can be difficult for coaches, because individuals with insecure attachment are not as trusting of adults due to the lack of support they received when they were younger (Harmon et al., 2015). Nevertheless, knowledge and awareness about attachment styles may help coaches to develop a positive relationship with different individuals and act appropriately in each situation.

\section{Social environment, motivational climate and coach-athlete relationship}

The social environment in which the players are immersed is a fundamental base for developing and maintaining a positive (secure) relationship (Harmon et al., 2015). Coaching behaviours that show openness, positivity, and autonomy allow athletes to feel they are supported and given attention, which would help increase the security in coach-athlete relationships (Harmon et al., 2015). For instance, during training sessions, a coach can provide instructions and organization, provide rationale for tasks/requests/constraints, encourages initiative taking or provide opportunity for player input (Smith et al., 2015). During competition, a coach can acknowledge feelings and perspective, engage in non-instructional conversation with athletes, recognize effort, or emphasizes task-focused competence feedback. This kind of environment during training and competition would increase the probability of youth and adolescent table-tennis players experiencing security. When players "who pose insecure attachment characteristics begin to feel that their environment is safe to explore, their security in the coach-athlete relationship will increase because they trust the environment the coach has constructed" (Harmon et al., 2015, pp.16).

As a whole, research provided strong evidence that coaches who employ autonomy-supportive behaviours can create an environment in which athletes feel their psychological needs are satisfied, thus allowing greater well-being (Felton \& Jowett, 2015; Harmon et al., 2015; Mageau \& Vallerand, 2003). As an illustration of this literature, a bulk of studies in several contexts (e.g., sport, school) showed that individuals immersed in training sessions favouring a choice condition (e.g., the player choose between several exercises, the player offers an exercise consistent with his game system) demonstrated higher intrinsically motivated behaviours than those involved in a no choice condition (Black \& Deci, 2000; Deci \& Ryan, 2000; Mageau \& Vallerand, 2003; Zuckermann, Porac, Lathin, Smith, \& Deci, 1978). Nevertheless, an autonomy-supportive coaching behaviour must not be confused with providing total freedom as highlighted by Mageau and Vallerand (2003) who emphasized the importance of providing choices within rules and limits in coaching. In particular, to support athletes' autonomy, coaches need to provide a rationale for requested tasks as well as for limits and rules in order to facilitate the internalization of the underlying reasons for activity engagement 
(Mageau \& Vallerand, 2003). As such, table tennis coaches need to set rules and limits for players and training groups to be able to work effectively. However, clear instructions may be perceived as controlling by players. As such, it is particularly important allowing table tennis players opportunities for initiative taking within a supportive relationship (Mageau \& Vallerand, 2003). When table tennis players are given the opportunity to take initiatives themselves their intrinsic motivation are strengthened. For instance, the problem-solving method is well suited in regards of taking initiatives. Thus, as a table tennis coach, finding the balance between instructive behaviour and giving freedom to choose and take initiatives, is an important issue to consider in the daily training sessions.

Moreover, autonomy-supportive coaches also inquire about and acknowledge athletes' feelings about the tasks and rules (Mageau \& Vallerand, 2003). This acknowledgement requires perspective taking on the coach's part. In this way the table tennis players most likely would feel recognized as persons as well, not only athletes. This would strengthen their self and their confidence, and they would be more likely to engage in the table tennis coach `s tasks and rules (Mageau \& Vallerand, 2003). For instance, it is important that during training sessions, coaches show care and concern for their table-tennis players, adopt a warm communication style, and show unconditional regard. In a similar vein, positive competence feedback is also acknowledged as a fundamental part of an autonomysupportive coaching style (Mageau \& Vallerand, 2003). It has been argued that positive feedbacks have two functional aspects: An informational and a controlling aspect (Ryan, 1982). When the informational aspect is salient and the controlling aspect is relatively non-salient positive feedback enhances people's perceptions of competence and thus fosters intrinsic motivation (Ryan, 1982). As such, giving positive feedback is not as straight forward as it may seem. If the feedback is provided with a clear and unambiguous message the impact on the intrinsic motivation is positive (e.g., "good placement on that forehand-topspin"). On the other hand, the same feedback with an inadequate formulation is not as effective: "good placement on that forehand-topspin. Do that more often!" The last part of this feedback possesses a controlling aspect and thus undermines the message and the athlete's intrinsic motivation.

Much feedback and behaviour can be controlling (e.g., overt control, controlling statements, guiltinducing criticisms, tangible rewards and encouragement of athletes' ego-involvement) and could restrain athletes' autonomy (Mageau \& Vallerand, 2003). Table tennis coaches can faulty believe that power comes with controlling behaviours such as using controlling language, relying on intimidation, demonstrating negative conditional regard, punishing mistakes, or restricting opportunities for interactions and conversation. However, feedback that appeals to the table tennis player's guilt, or just is excessively controlling, is disrupting to their intrinsic motivation. This kind of communication is also an abuse of power and would decrease the players trust in the coach. Coaches' awareness of their own way of communicating, and the effect of their feedback, is essential for promoting autonomy-supportive coaching behaviours.

\section{Communication skills at the service of the coach- athlete relationship}

When table tennis coaches communicate with their players, increasing the chance that players have received, accepted and understood the message according to the coach's wishes is a particularly salient issue. In this way, Dominteanu (2014) elaborated on the questions that can guide coaches before communicating with their players: "Why they want to communicate? Who they want to communicate with? Where and when the message could best be delivered? What do they want to communicate? How are they going to communicate?" (pp. 512). He also explained that effective communication is characterized by six elements: Be clear, concise, correct, complete, courteous and constructive.

Sport settings and its inherent pressure might consistently influence the communication between 
coaches and players. Difficulties in the communication can come from several clues including interfering emotions, the coach's and athlete's different perceptions or communication technical obstacles (Dominteanu, 2014). Because coach athlete relationship is dynamic, the way coaches communicate is an important factor causing the players' responsiveness to feedback (Ihlen, Ihlen, $\&$ Koss, 2011). The amount of instruction the players can receive and accept is affected by the total amount of feedback, and the amount of instructional feedback/corrections versus positive feedback provided by the coach. Instructions and feedbacks are a natural part of the coaching role, but coaches should count themselves responsible for how their feedbacks are received by players. Over communicating can make players get bored or even irritated when receiving instructions. Too much instructions or corrections can thus make players less responsive (Ihlen et al., 2011). Positive feedbacks should be the largest part of the total amount of feedbacks in order to build the players' confidence and autonomous motivation and to increase the players' responsiveness to further instructions or corrections (Mageau \& Vallerand, 2003).

Otherwise, table tennis coaches should be aware of the central role of non-verbal behaviours in the communication (Ledos, Martinent, Decret, \& Nicolas, 2013; Martinent, Ledos, \& Nicolas, 2016). In order to be clear when communicating, the bodylanguage of the coaches should conform to the verbal message (Dominteanu, 2014). Alternatively, coaches should also be aware of the non-verbal behaviours expressed by the athlete's body language (e.g., facial expressions, body posture). These signs provide rich information about the mental state of players or the group of players (Dominteanu, 2014).

In sum, the complexity of communication with its verbal and non-verbal components shows how demanding coaching is. To communicate effectively with different players requires a lot, and effective communication skills are vital (Dominteanu, 2014). Thus, awareness and knowledge about communication would help table tennis coaches to communicate appropriately with their players.
Whereas good communication skills are necessary for allowing coaches to develop and maintain the relationship with their players, a positive coach athlete relationship is necessary to understand the athlete, and thus to minimize the risks of interference in the communication. As such, the coach-athlete relationship and the quality of the communication are strongly influenced by each other (Dominteanu, 2014).

\section{Maintenance of the coach-athlete relationship: The role of openness and conflict management}

Openness and conflict management play significant roles in maintaining a positive coachathlete relationship (Rhind \& Jowett, 2010). Openness refers to the three inter-related dimensions of non-sport communication, talking about anything, and other awareness (making an attempt to understand how the player is feeling) (Rhind \& Jowett, 2010). Openness is an important contributor to the table tennis player's experience of being seen and heard as a person, not only as an athlete. If the athlete feels secure about bringing up any issue with the coach, it strengthens the athlete`s trust in the coach and thereby the relationship between the two stakeholders. Nevertheless, some disagreements or conflicts are unavoidable between table tennis players and coaches within the daily training sessions. How disagreements or conflicts are handled strongly influence the relationship (Rhind \& Jowett, 2010). It is noteworthy that conflict management not only considers co-operative acts during disagreements but also pre-emptive strategies (e.g., clarifying the expectations and the consequences when these are not met) (Rhind \& Jowett, 2010). For instance, performing autonomysupportive coaching behaviours can be considered as a preventative action itself (Mageau \& Vallerand, 2003). Indeed, giving athletes the opportunity to take part in decisions (and/or make choices) in training and during competition certainly reduces the occurrence of conflicts. Clarification of expectations from both parties is another important preventive action that can create fundament of further 
cooperation, and hopefully keep the prevalence of conflicts rather low (Rhind \& Jowett, 2010).

When conflicts occur, the aforementioned preventative measures could serve as primary buffering (Rhind \& Jowett, 2010). For instance, with clarifying expectations through dialog with the players, table tennis coaches would: (a) allow athletes to influence the terms themselves, and (b) be able to explain in a good way how they want to cooperate with their players. Aforementioned communication issues are also particularly salient for conflict management (Dominteanu, 2014). For instance, clear and concise communications is vital in conflict management (Dominteanu, 2014). Nevertheless, knowing exactly how to solve a given conflict is probably illusory because it can be affected by the context, the persons involved or the interaction between the context and the individuals. In any case, addressing the actions causing the conflict, not the person, is especially wise (Dominteanu, 2014). With the common expectations as a fundament, the chance of solving the problem and be able to move forward without impairing the relationship is substantial (Rhind \& Jowett, 2010).

\section{Coaching behaviours during table tennis competitions}

Coping is inherent to the lives of table tennis players participating in competition given the high psychological demands placed on them (Chen et al., 2010; Martinent, Campo, \& Ferrand, 2012). Indeed, there is a general agreement among table tennis players, table tennis coaches and sport psychologists that achievement of performance goals depends partly on players' capacity to cope with the various demands encountered in these competitions and to manage emotions experienced during competition (Chen et al., 2010; Kurimay et al., 2017; Martinent \& Ferrand, 2009, 2015a; Martinent et al., 2015). A player`s possession of effective coping strategies during competition is important to be able to enjoy the competition and to reach its full potential in the competition (Martinent et al., 2015). Although everybody wants to win, the focus during table tennis competition should be directed towards relevant tasks such as strategic thinking and tactical tasks in order to perform well (and thus increase the chance of winning) (Kurimay et al., 2017). The players' perception of the importance of the event can easily cause them being too caught up in the occasion (Martinent \& Ferrand, 2015b). And this issue doesn `t only apply for players, but coaches as well. Coaches who are aware of their own mindset and behaviours during competitions are more likely to control how they influence their player's coping strategies, which in turn could influence their players' emotions during competition (GonzálezGarcía \& Martinent, in press). Especially, Nicolas et al. (2011) highlighted that supportive coach behaviour (the feeling that your coach encourages you) was positively linked with the use of functional coping strategies meanwhile unsupportive coach behaviour (the feeling of discouragement from coach) was positively related to the use of dysfunctional coping strategies.

As leading by example is a positive attribute of leadership (Chelladurai, 1990; Jowett \& Poczwardowski, 2007), perceived stability and support from coaches is important for table tennis players during matches. Table tennis players experience a wide variety of emotions during matches (Martinent \& Ferrand, 2009; Martinent et al., 2012; Sève, Ria, Poizat, Saury, \& Durand, 2007). Different opponents, outcome of matches, satisfaction with their own actual playing level, perceived pressure from parents or significant others are factors that can influence their emotions (Martinent \& Ferrand, 2015b; Sève et al., 2007). Players don't need any more pressure than they already are dealing with and they are in no need of handling inexpedient emotions and behaviours of their coach (Martinent et al., 2015). If table tennis coaches want their players to handle their emotions and perform well, coaches should handle their own emotions and be aware of their effect on the players. Indeed, to distinguish between his/her own needs and what the players need is highly relevant in this matter. If coaches stay positive and focused towards relevant tasks, the players are more likely to do the 
same (González-García \& Martinent, in press). Leading by example is therefore essential.

\section{Conlusion}

The present narrative review highlighted the importance of initiating and maintaining a harmonious relationship between coaches and athletes. The reasoning behind is comprehensive and complex. On one hand, a bulk of studies conducted among table tennis players provided evidence of the main role played by psychological factors (motivation, emotions, coping strategies) in players' performance and well-being (Chu et al., 2018; González-García \& Martinent, 2019; Kurimay et al., 2017; Martinent \& Decret, 2015a; Martinent et al., $2015,2018)$. On the other hand, a growing number of studies conducted in table-tennis provided evidence of the impact of coaches' behaviours on table tennis players' psychological outcomes (González-García \& Martinent, in press; Kajtna \& Kondric, 2009; Li-Hua et al., 2012). Indeed, developing and maintaining a harmonious coachathlete relationship is of prime importance for the different stakeholders involved in table tennis (coaches, players, organizations).

In this way, establishing an autonomy supportive coaching style (providing choices within rules and limits, acknowledge athletes' emotions, using positive feedbacks) is particularly useful for creating an environment likely to engender a harmonious coach-athlete relationship in the interest of both parties (Mageau \& Vallerand, 2003). Attachment styles, communication skills, openness, and conflict management are also main elements to consider for optimizing coach-athlete relationship (Dominteanu, 2014; Harmon et al., 2015; Rhind \& Jowett, 2010). Multiple beneficial effects of an autonomy supportive coaching style have been detailed in this study. Nevertheless, the use of an autonomy-supportive coaching style is not without negative effects. Especially a strong coach-athlete relationship could potentially become too prominent and excessive. Jowett and Poczwardowski (2007) emphasized that closeness must be satisfied in a well-functioning coach-athlete relationship. Keeping the right balance in this matter in the relationship is important. For many table tennis players, the coach plays a key role in their everyday life, and bands between coaches and athletes can become tight. The coach should keep in mind that the closeness in the relationship doesn't blurry his/her overview and his ability to provide clear and concise feedback and set limits when necessary.

According to Jowett and Pochwardowski (2007) relationships are expected to change over time. The coach's awareness about the evolvement of the relationship in line with the players' level and growth is an important issue. Throughout a long career a lot of adjustments need to be made. The stage when young table tennis players are entering teenager is one to pay attention to. Younger players possess lower knowledge and are therefore often more likely to just follow instructions. As time goes, and the player develops, the coach should be able to adjust the communication to be most suitable according to the stage of the players' career. Even though the coach performs an autonomy-supportive coaching style, the risk of giving too much instruction is often something to be aware of. When young players become teenagers, their need of making their own choices is usually increased. The balance between instructions, giving opportunities of making choices and taking initiatives is thus in constant adjustment. Without losing track of the athletic development, dialog becomes even more important. Letting table tennis players making choices and taking more initiatives should be a more prominent part of the communication with aging. It can be challenging for a coach to give more responsibility to the players worrying that the athletes will make too many bad decisions. Nevertheless, in order to let the players learn and grow, they need to get the chance to make those decisions. Even if they make some bad ones, it contributes to their motivation. In the long run hopefully, this will increase the chance of fulfilling their potential. 


\section{References}

Black, A. E., \& Deci, E. L. (2000). The effects of instructors' autonomy support and students' autonomous motivation on learning organic chemistry: A self-determination theory perspective. Science Education, 84, 740-756.

Bowlby, J. (1982). Attachment and loss: Attachment ( $\left.2^{\text {nd }} E d.\right)$. London: Basic Books.

Campo, M., Mackie, D. M., \& Sanchez, X. (2019). Emotions in group sports: A narrative review from a social identity perspective. Frontiers in Psychology, 10, 666.

Cece, V., Guillet-Descas, E., Nicaise, V., Lienhart, N., \& Martinent, G. (2019). Longitudinal trajectories of emotions among young athletes involving in intense training centres: Do emotional intelligence and emotional regulation matter? Psychology of Sport and Exercise, 43, 128-136.

Cece, V., Lienhart, N., Nicaise, V., Guillet-Descas, E., \& Martinent, G. (2018). Longitudinal sport motivation among young athletes in intensive training settings. The role of basic psychological needs satisfaction and thwarting in the profiles of motivation. Journal of Sport \& Exercise Psychology, 40, 186-195.

Chelladurai, P., \& Saleh, S. D. (1980). Dimensions of leader behavior in sports: Development of a leadership scale. Journal of Sport Psychology, 2, 34-45.

Chelladurai, P. (1990). Leadership in sport: A review. International Journal of Sport Psychology, 21, 328-354.

Chen, I., Chang, C., Hung, C. L., Chen, L. C., \& Hung, T. M. (2010). Investigation of underlying psychological factors in elite table tennis players. International Journal of Table Tennis Sciences, 6, 48-50.

Chu, T. L., Zhang, T. \& Hung T. M. (2018). Motivational profiles in table tennis players: Relations with performance anxiety and subjective vitality. Journal of Sports Sciences, 36, 2738-2750.

Cipriani, A., \& Geddes, J. (2003). Comparison of systematic and narrative reviews: The example of the atypical antipsychotics. Epidemiology and Psychiatric Sciences, 12, 146-153.
Davis, L., \& Jowett, S. (2014). Coach-athlete attachment and the quality of the coach-athlete relationship: implications for athlete`s well-being. Journal of Sports Sciences, 32, 1254-1464.

Deci, E. L., \& Ryan, R. M. (2000). The "what" and "why" of goal pursuits: Human needs and the selfdetermination of behavior. Psychological Inquiry, 11, 227-268.

Dominteanu, T. (2011). The significance of the coach-athlete relationship. Indian Journal of Applied Research, 4, 512-513.

Drake, D. B. (2009). Using attachment theory in coaching leaders: The search for a coherent narrative. International Coaching Psychology Review, 4, 49-58.

Felton, L., \& Jowett, S. (2015). On understanding the role of need thwarting in the association between athlete attachment and well/ill-being. Scandinavian Journal of Medicine \& Science in Sports, 25, 289-298.

Gaudreau, P., \& Blondin, J. P. (2002). Development of a questionnaire for the assessment of coping strategies employed by athletes in competitive sport settings. Psychology of Sport and Exercise, 3, 1-34.

González-García, H., Martinent, G., \& Trinidad Morales, A. (2019). Perceived coach leadership profiles and relationship with burnout, coping and emotions. Frontiers in Psychology, 10, 1785.

González-García, H., \& Martinent, G. (2019). Influence of sport-practice-hours on burnout and coping in table tennis players. International Journal of Racket Sports Science, 1, 15-23.

González-García, H., \& Martinent, G. (in press). Relationships between perceived coach leadership, athletes' use of coping and emotions among competitive table tennis players. European Journal of Sport Science. doi:10.1080/17461391.2019.1693633

Harmon, H., Siegien, J., Watt, C., Rebers, K., \& Pennington, C. G. (2019). Attachment theory in coach-athlete relationships. Professional Association of Athlete Development Specialists Research Digest, 3, 14-16.

Ihlen, B. M., Ihlen, H., \& Koss, J. O. (2011). Effekt: Falske smil og ekte ørefiker. Oslo: Cappelen Publishing.

Jowett, S., \& Davis, L. (2014). Coach-athlete attachment and the quality of coach-athlete 
relationship: Implications for athlete`s well-being. Journal of Sports Science, 32, 1454-1464.

Jowett, S., \& Poczwardowski, A. (2007). Understanding the coach-athlete relationship. In S. Jowett \& D. Lavallee (Eds.), Social psychology in sport (pp. 3-14). Champaign, IL: Human Kinetics.

Kajtna, T., \& Kondric, M. (2009). Top coaches in table tennis and other sports. International Journal of Physical Education, 46, 24-31.

Kurimay, D., Pope-Rhodius, A., \& Kondric, M. (2017). The relationship between stress and coping in table tennis. Journal of Human Kinetics, 55, 75-81.

LaVoi, N. M. (2004, September). Dimensions of closeness and conflict in the coach-athlete relationship. Paper presented at the meeting of the Association for the Advancement of Applied Sport Psychology, Minneapolis, MN.

LaVoi, N. M. (2007) Expanding the interpersonal dimension: Closeness in the coach-athlete relationship. International Journal of Sport Science \& Coaching, 2, 497-512.

Ledos, S., Martinent, G., Decret, J-C., \& Nicolas, M. (2013). Non-verbal behavior-performance relationship among a sample of international table tennis players. International Journal of Table Tennis Sciences, 8, 101-104.

Li-Hua, L., Cheng-Hua, H., \& Chung-Hsiung, H. (2012). University table tennis players' perception on coaches' leadership behaviour. International Journal of Table Tennis Science, 7, 37-41.

Mageau, A. G., \& Vallerand, R. J. (2003). The coach-athlete relationship: A motivational model. Journal of Sports Sciences, 21, 893-904.

Martinent, G., Campo, M., \& Ferrand, C. (2012). A descriptive study of emotional process during competition: Nature, frequency, direction, duration and co-occurrence of discrete emotions. Psychology of Sport and Exercise, 13, 142-151.

Martinent, G., Cece, V., Elferink-Gemser, M., Faber, I., \& Decret, J.-C. (2018). The prognostic relevance of psychological factors with regard to participation and success in table-tennis. Journal of Sports Sciences, 36, 2724-2731.

Martinent, G., \& Decret, J.-C. (2015a). Motivational profiles among young table-tennis players in intensive training settings: A latent profile transition analysis. Journal of Applied Sport Psychology, 27, 268-287.

Martinent, G., \& Decret, J.-C. (2015b). Coping profiles of young athletes in their everyday life: A three-wave two-month study. European Journal of Sport Science, 15, 736-747.

Martinent, G., Ledos, S., Ferrand, C., Campo, M., \& Nicolas, M. (2015). Athletes' regulation of emotions experienced during competition: A naturalistic video-assisted study. Sport, Exercise, and Performance Psychology, 4, 188-205.

Martinent, G., Ledos, S., \& Nicolas, M. (2016). Mesures des émotions en sport : Les approches quantitatives, qualitatives et comportementales. In M. Campo and B. Louvet (Eds.), Les émotions en sport et en EPS : Enseignement, performance et santé (pp. 211227). Bruxelles: Editions De Boeck.

Martinent, G., \& Ferrand, C. (2009). A naturalistic study of the directional interpretation process of discrete emotions during high-stakes table tennis matches. Journal of Sport and Exercise Psychology, 31, 318-336.

Martinent, G., \& Ferrand, C. (2015a). Are facilitating emotions really facilitative? A field study of the relationships between discrete emotions and objective performance during competition. International Journal of Performance Analysis in Sport, 15, 501-512.

Martinent, G., \& Ferrand, C. (2015b). A field study of discrete emotions: Athletes' cognitive appraisals during competition. Research Quarterly for Exercise and Sport, 86, 51-62.

Nicolas, M., Gaudreau, P., \& Franche, V. (2011). Perception of coaching behaviours, coping, and achievement in a sport competition. Journal of Sport $\mathcal{E}$ Exercise Psychology, 33, 460-468.

Rhind, D. J. A., \& Jowett, S. (2010). Relation maintenance strategies in the coach-athlete relationship: The development of the COMPASS model. Journal of Applied Sport Psychology, 22, 106-121.

Ryan, R. M. (1982). Control and information in the intrapersonal sphere: an extension of cognitive evaluation theory. Journal of Personality and Social Psychology, 43, 450-461. 
Sève, C., Ria, L., Poizat, G., Saury, J., \& Durand, M. (2007). Performance-induced emotions experienced during high-stakes table tennis matches. Psychology of Sport and Exercise, 8, 25-46.

Smith, N., Tessier, D., Tzioumakis, Y., Quested, E., Appleton, P., Sarrazin, P., Papaioannou, A., \& Duda, J. L. (2015). Development and validation of the multidimensional motivational climate observation system. Journal of Sport \& Exercise Psychology, 37, 4-22.
Wyllemann, P. (2000). Interpersonal relationships in sport: Uncharted territory in sport psychology research. International Journal of Sport Psychology, 31, 555-572.

Zuckerman, M., Porac, J., Lathin, D., Smith, R., \& Deci, E.L. (1978). On the importance of selfdetermination for intrinsically motivated behavior. Personality and Social Psychology Bulletin, 4, 443-446. 